\title{
Thoracic surgery education in Canada
}

\author{
Sean C. Grondin, MD, MPH, FRCSC, and Colin Schieman, MD
}

\author{
From the Department of Surgery, Section of Thoracic Surgery, University of Calgary, Calgary, Alberta, Canada. \\ Disclosures: Authors have nothing to disclose with regard to commercial support. \\ Received for publication April 1, 2016; revisions received Sept 4, 2016; accepted for publication Sept 22, 2016; \\ available ahead of print Nov 18, 2016. \\ Address for reprints: Sean C. Grondin, MD, MPH, FRCSC, University of Calgary, Foothills Medical Center, 1403 \\ 29th St NW, Room G 33 D, Calgary, Alberta, Canada T2N 2T9 (E-mail: sean.grondin@ahs.ca). \\ J Thorac Cardiovasc Surg 2017;153:493-7 \\ $0022-5223 / \$ 36.00$ \\ Copyright (C) 2016 by The American Association for Thoracic Surgery \\ http://dx.doi.org/10.1016/j.jtcvs.2016.09.082
}

In the 1930s, innovative efforts by a pioneering group of general surgeons led by Drs Edward Archibald and Norman Bethune marked the early development of thoracic surgery in Canada. ${ }^{1}$ Initially their efforts focused on the treatment of war-related chest wounds in surviving soldiers; however, the broad expansion of surgical treatment of septic diseases of the lung and pleura due to tuberculosis provided them the opportunity to improve their thoracic skills by treating civilians. With the development of improved anesthetics techniques the indications for thoracic surgery expanded to include elective resections for lung cancer. ${ }^{2}$ Formal thoracic surgery training began in 1946 under the auspices of the Royal College of Physicians and Surgeons Canada (RCPSC) to accommodate the growing need for specialists in the field of thoracic surgery. In 1962, The RCPSC established a 3-year combined qualification program in cardiovascular and thoracic surgery for which a completed general surgery residency was a prerequisite. Recognizing the need for specialized training in the evolving specialty of general thoracic surgery, surgical educators led by Dr F. G. Pearson obtained approval by the RCPSC for a certificate of special competence in thoracic surgery in $1978 .^{2}$ In an effort to reduce the length of training, the RCPSC approved separate primary specialty status (ie, direct entry from medical school) for cardiac and general thoracic surgery in 1994. ${ }^{3,4}$ To date, cardiac surgery has remained a primary specialty, whereas thoracic surgery reverted back to a subspecialty in 2002 . Table 1 summarizes the important events in the evolution of thoracic surgery education in Canada.

There are currently 8 RCPSC-accredited thoracic surgery residency programs in Canada (Table 2). Formal program accreditation is highly prescriptive, and extensive teambased reviews of the entire academic and administrative structure of the program occur with a final credentialing ruling. Maintenance of accreditation requires the training program demonstrate that it is successfully teaching all of the RCPSC Goals and Objectives of Training in Thoracic Surgery and incorporating a multifaceted assessment of resident performance. ${ }^{5}$ Other program components assessed during accreditation include the structure and

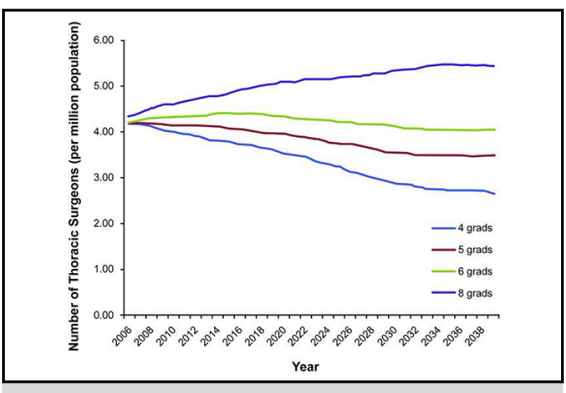

Projected number of thoracic surgeons according to number of trainees produced annually.

\section{Central Message}

In 1978, the Royal College approved a certificate of special competence in thoracic surgery. Currently there are 8 accredited thoracic surgery residency programs graduating 6 to 8 residents per year.

\section{Perspective}

In 1978, the Royal College approved a certificate of special competence in thoracic surgery. Currently, there are 8 accredited thoracic surgery residency training programs in Canada graduating 6 to 8 residents per year. Future educational priorities include refining the scope of practice for thoracic surgery, accurately forecasting workforce needs, and implementing competency-based medical education.

See Editorial Commentary page 498.

organization of the program as well as the functionality of the administrative structure of the program (eg, Residency Training Committee), including the effectiveness of the Program Director and Program Assistant. The clinical, academic, and scholarly content of the program, as well as resources available to the Program Director and residents are evaluated. ${ }^{6}$ Programs are accredited by the RCPSC at 3-year intervals: an internal review (year 3) and external review (year 6) is the typical cycle.

Scanning this QR code will take you to the article title page.

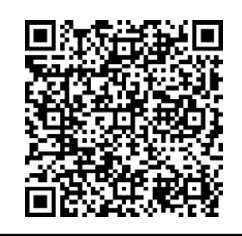


TABLE 1. Important dates in the evolution of thoracic surgery education in Canada

\begin{tabular}{ll}
\hline \multicolumn{1}{c}{ Event } & Year \\
\hline RCPSC certifies the specialty of thoracic surgery & 1946 \\
RCPSC defines the combined fellowship in CVT surgery & 1961 \\
Certificate of competence in thoracic surgery approved by RCPSC & 1978 \\
RCPSC recognizes thoracic surgery as a primary specialty & 1994 \\
Canadian Association of Thoracic Surgeons (CATS) Established & 1998 \\
RCPSC reverts thoracic surgery to a secondary subspecialty & 2002 \\
RCPSC CanMEDS framework introduced & 2005 \\
RCPSC CanMEDS CBD introduced & 2015 \\
RCPSC CBME to be implemented & 2020 \\
\hline$R C P S C$, Royal College of Physicians and Surgeons of Canada; CVT, cardiovascular \\
and thoracic; CBD, Competency by Design; CBME, Competency-Based Medical \\
Education Program.
\end{tabular}

The academic calendar year for each program begins July 1 . There are varying numbers of residents across programs, with some training 1 resident every 2 years whereas others accepting 2 residents every year. The application deadline for programs accepting residents is January 2nd (18 months before the start of the program). In most years, the number of applicants exceeds the number of available training positions. Priority for admission usually is given to residents completing general surgery training in Canada. Only 1 or 2 foreign graduates are trained every 2 years in Canada by programs such as the University of Western Ontario, which will offer residency training to foreign graduates based on predetermined arrangements with various Middle Eastern countries such as Saudi Arabia. Receiving credit for foreign training in thoracic surgery in an effort to obtain certification in Canada is challenging and stringently controlled by the Royal College of Physicians and Surgeons to maintain high standards of excellence.

The current curriculum for thoracic residency programs is based on the CanMEDS 2005 physician competency framework, recently updated to "CanMEDS 2015." This framework defines distinct but related roles for graduates under the headings of "Medical Expert," "Communicator," "Collaborator," "Scholar," "Professional," "Leader," and "Health Advocate" (Figure 1). ${ }^{8,9}$ The CanMEDS construct is common to all postgraduate medical residencies in Canada. The 2015 RCPSC
National Curriculum Guide for Thoracic Surgery and the current RCPSC Objectives of Training in the Subspecialty of Thoracic Surgery are based on the CanMEDS framework and are available at the RCPSC website. ${ }^{5,10}$ The RCPSC Specialty Committee in Thoracic Surgery meets twice a year to discuss modifications to the educational goals and objectives and to review program accreditation standards while serving as a liaison between the specialty and the RCPSC. The RCPSC Specialty Committee in Thoracic Surgery is distinct from the RCPSC Thoracic Surgery Exam Committee.

The majority of residents entering thoracic surgery have completed a general surgery residency before admission. Current RCPSC Subspecialty Training Requirements in Thoracic Surgery are listed on the Royal College website. ${ }^{11}$ Interestingly, direct-entry programs (similar to the current I-6 programs in the United States) were trialed at the University of Toronto and the University of Manitoba in the 1990s, but were abandoned in Canada because of a lack of suitable applicants and insufficient training in general surgery for applicants to be competent in foregut surgery. ${ }^{4,12}$ Typically, the thoracic residency is 2 years in length with rotations in both general thoracic surgery (18 months) and cardiac surgery (3 months). Three months of elective time is provided, and trainees may undertake rotations in areas of interest such as community-based thoracic surgery, thoracic radiology, interventional pulmonology, advanced endoscopy, transplantation, minimally invasive surgery, oncology, and research. A 2009 survey by the Canadian Association of Thoracic Surgeons (CATS) reported residents are predominantly male with an average age of $34 .{ }^{13}$ Although all programs are expected to adhere to work hour restrictions, residents reported working greater than 70 hours per week with a 1:3 or 1:4 call schedule. ${ }^{14}$

Additional fellowship training after residency occasionally is sought by trainees who have specialized interest. Commonly these fellowships are sought in centers of excellence in the United States; however, fellowship opportunities also are available in Canada for a variety of interests, including, for example, the Tracheo-bronchial and Oesophageal Center Advanced Interventional Thoracic Endoscopy Fellowship at l'Université de Montreal and

TABLE 2. Current thoracic surgery training programs in Canada

\begin{tabular}{lll}
\hline \multicolumn{1}{c}{ Program (year established) } & \multicolumn{1}{c}{ Location } & Program director \\
\hline University of British Columbia (1985) & Vancouver & Dr John Yee \\
University of Calgary (2004) & Calgary & Dr Colin Schieman \\
University of Manitoba (1989) & Winnipeg & Dr Gordon Buduhan \\
University of Western Ontario (1987) & London & Dr Dalilah Fortin \\
McMaster University (2002) & Hamilton & Dr Christian Finley \\
University of Toronto (1966) & Toronto & Dr Andrew Pierre \\
University of Ottawa (1978) & Ottawa & Dr Patrick J. Villeneuve \\
University of Montreal and Laval University (1997) & Montreal and Quebec City & Dr Jocelyn Martin y \\
\hline
\end{tabular}




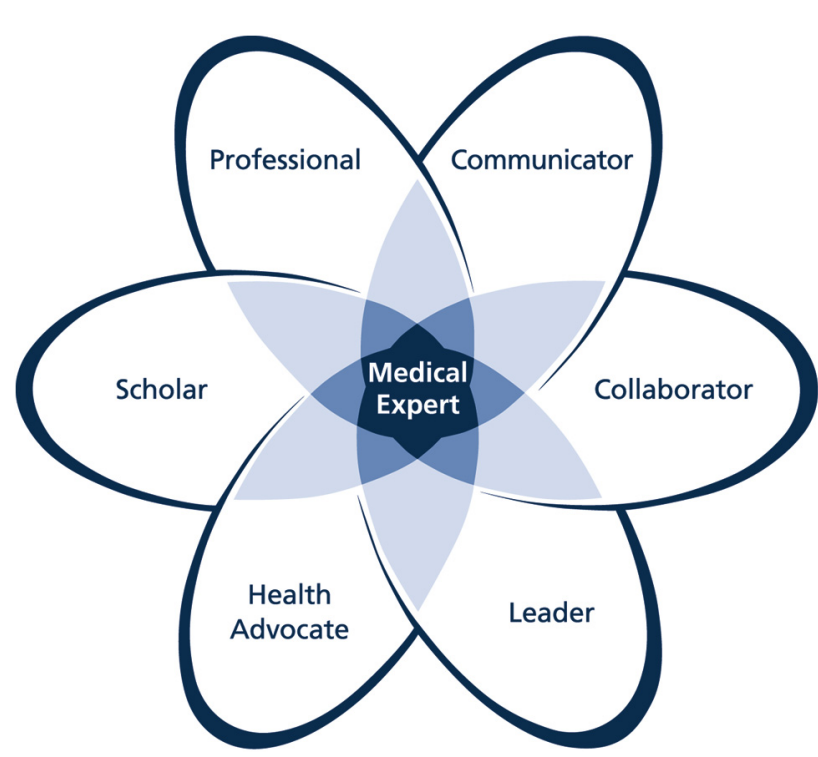

FIGURE 1. The Royal College of Physicians and Surgeons of Canada CanMEDS Framework. Copyright (C) 2015 The Royal College of Physicians and Surgeons of Canada. http://rcpsc.medical.org/canmeds. Reproduced with permission.

Lung Transplantation Fellowship at the University of Toronto. To date, it is unclear whether these fellowships are sought because of a perceived lack of comfort performing thoracic surgery procedures at the completion of the 2-year residency or as a means to bolster an applicant's resume in a competitive job market. Some trainees also chose to complete additional postgraduate training during or after their residency by completing advanced degrees in clinical research or medical education. Approximately $50 \%$ of thoracic surgery residents already possess an advanced degree at the time of their enrollment in a thoracic surgery program. ${ }^{14}$ Although the current model for training has been successful, areas of weaknesses in training were identified in a 2014 study by Edwards and colleagues ${ }^{15}$ when comparing the perceptions of residents and program directors as they relate to residents' ability to perform 19 core thoracic surgery procedures independently. Both residents and program directors identified first rib resections, lung transplantation, and extrapleural pneumonectomy as procedures for which residents were not prepared adequately to perform independently at the end of their training. Additional information on self-reported resident and junior thoracic surgeons $(<5$ years into practice) comfort levels to perform core thoracic surgery procedures also was obtained. ${ }^{16}$ Residents reported only adequate or better experience for 9 of 18 procedures compared with 10 of 18 procedures for junior staff. Procedures such as lung transplantation, first rib resection, and surgery for mesothelioma were once again highlighted as core procedures that residents and junior staff were less comfortable performing in addition to interventional pulmonary procedures and minimally invasive esophageal surgery techniques. Eight of 16 staff reported completing extra fellowship training at the completion of their thoracic surgery residency training. These studies helped identify potential weaknesses in training and led surgical educators to address gaps in educational curricula by creating an annual thoracic surgery boot camp at the University of Toronto under the Directorship of Dr Kazuhiro Yasufuku. To date, gaps that have been targeted for review at the boot camp include minimally invasive foregut surgery (eg, laparoscopic Heller myotomy, peroral endoscopic myotomy) as well as endobronchial ultrasound techniques. Feedback surveys from thoracic surgery residents at the completion of the boot camp strongly have suggested that this approach has been successful in addressing some of the gaps in ability.

Throughout their 2-year residency trainees are evaluated at 3- to 6-month intervals with in-training evaluation reports. Data for the evaluative process vary from program to program but usually is based on direct observation in the clinical setting, 360 evaluations by allied health professionals, and practice written and oral examinations. Some programs also have their trainees complete the American Board of Thoracic Surgery in Training Exam. Logbooks of operations performed by residents and training portfolios are additional sources for feedback. Near the completion of the 2-year residency, trainees receive a final in-training evaluation report, which is completed by the program director with input from the residency training committee members. Trainees who have completed successfully a 2-year program typically take their examinations approximately 3 months after the completion of training.

The examination is overseen by the RCPSC and consists of 2 parts: a written and oral component. The written component comprises a 3-hour exam of 70 short-answer questions designed to assess both clinical thoracic surgery and clinically applied basic science knowledge. The oral component consists of two 1-hour oral sessions with each session consisting of 4 clinical scenarios. The candidate is asked oral questions dealing with thoracic surgery, the related basic sciences, and the relevant aspects of cardiac surgery, critical care, and general surgery. Although pass/fail rates are not available officially from the RCPSC, an informal poll of former Chairs of the RCPSC Exam Committee estimates a successful pass rate of $85 \%$ to $90 \%$ for both written and oral examinations.

Looking ahead, one important priority in thoracic surgery education in Canada is defining accurately the scope of practice for thoracic surgeons. Achieving this goal will facilitate refinement of educational goals and objectives and direct the core surgical procedures that 
should be mastered by trainees prior to entering practice. In 2004, Dr Darling and colleagues ${ }^{4}$ published the first article attempting to define the scope of thoracic surgery practice in Canada. In this important article, a detailed survey was created to assist in developing standards of practice as well as training and resource requirements for the practice of thoracic surgery in Canada. The authors recommended that appropriate training in thoracic surgery include the completion and certification in general or cardiac surgery before completing a 2-year thoracic surgery residency program and that the practice of thoracic surgery include the diagnosis and management of conditions of the lung, mediastinum, pleura, and foregut. The article further concluded that thoracic surgery care was best delivered in regional centers by 2 or 3 fully certified thoracic surgeons supported by cancer and trauma units. This concept has been shown to result in improved patient outcomes by facilitating multidisciplinary and interdisciplinary assessment as well as allowing for adequate coverage for on-call and continuing medical education. ${ }^{17}$ As part of the CATS 2016 strategic planning initiative, a review of the scope of practice will be performed to ensure current standards include new technologies such as endobronchial ultrasound. This revised list of thoracic diseases and procedures will help define core procedures that all thoracic surgery residents should be comfortable and competent to perform after training versus procedures that require additional training such as lung transplantation.

Another significant challenge in thoracic surgery education is predicting accurately thoracic surgery workforce requirements. Accurate forecasting ensures that government agencies are able to allocate appropriate resources on a provincial and national level and regulate the number of thoracic surgery residency positions to balance the amount of graduates with job availability. In 2009, the Thoracic Manpower and Education Survey was completed by CATS members and served as the basis for developing a model for predicting thoracic surgery workforce requirements in Canada. ${ }^{13}$ This novel microsimulation model was based on the Canadian Community Health Survey and Canadian Census data and suggests that at the current rate of training (6 trainees graduating per year), the appropriate number of thoracic surgeons is currently being trained to meet the future needs of the Canadian population until 2030 (Figure 2). ${ }^{18}$ The model was further refined to assess the impact of computed tomographic screening and stereotactic ablative therapy for early lung cancers on forecasting workforce needs. ${ }^{19,20}$

Importantly, even the addition of 1 or 2 graduates per year was predicted to have significant impact on the potential mismatch of surgeons and available positions. These studies highlight the importance of carefully monitoring thoracic surgery residency training positions to ensure that the

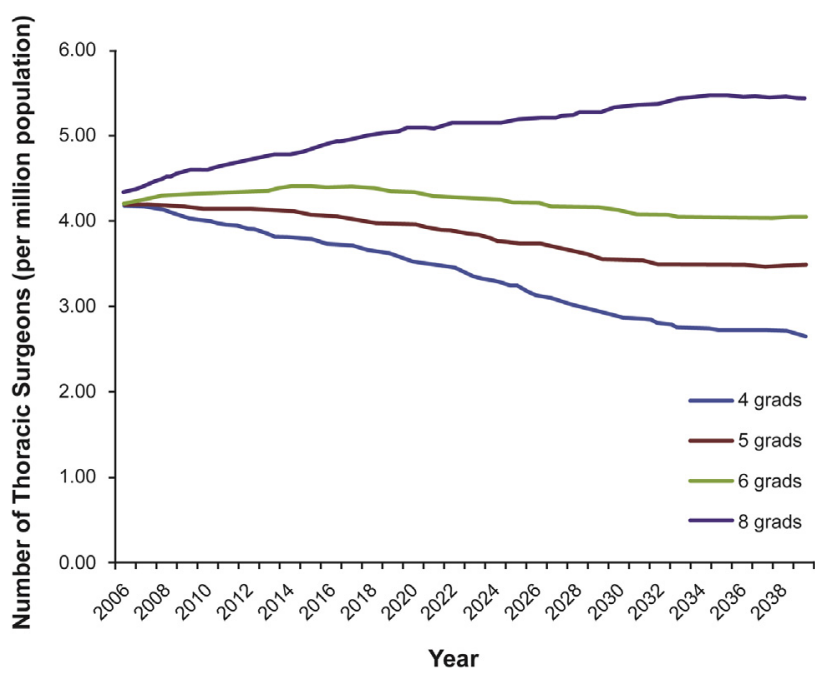

FIGURE 2. Projected number of thoracic surgeons per million until 2030, with variation demonstrated according to number of trainees produced annually. Reproduced with permission from Edwards and colleagues. ${ }^{18}$

supply of graduating surgeons does not outstrip job availability. At this time, the number of thoracic surgery training positions cannot easily be changed and is not regulated by a national policy. A strategy is however required from stakeholders (ie, RCPSC, CATS, and government agencies) to ensure that an appropriate number of surgeons are being trained to meet the future needs of the population of Canada.

Another critical task for thoracic surgery educators in Canada is the implementation of the 2015 CanMEDS framework as part of the RCPSC's ambitious plan to implement nationwide and specialty wide Competency by Design (CBD). ${ }^{7,21}$ At its core, CBD switches the emphasis of training to the practice of assessing trainees' progressive achievement of competence over the course of an entire training program compared with the traditional practice of credentialing surgeons solely based on time spent on rotations. This new approach to thoracic education is outlined in the CanMEDS 2015 CBD competence continuum that represents a thoracic surgeons career from entry into residency, mastery of the core discipline, transition into practice, continuing professional development, and subsequent transition out of practice. ${ }^{7,21}$ This transformational initiative was developed to enhance competency-based medical education (CBME) in residency training and specialty practice in Canada. CBME is an outcomes-based approach to the design, implementation, assessment, and evaluation of a medical education program using an organizing framework of competencies. ${ }^{22}$ It is anticipated that the RCPSC Specialty Committee in Thoracic Surgery will implement a CBME curriculum in 2020. The impact and resources required to implement $\mathrm{CBD}$ in thoracic training remain unclear and are an 
important topic of discussion for the Thoracic Surgery Subspecialty Committee.

In summary, the training of thoracic surgeons in Canada has evolved from the establishment of a combined qualification in cardiovascular and thoracic surgery by the RCPSC to the emergence of thoracic surgery as a distinct subspecialty residency program. Currently, there are 8 RCPSC-accredited thoracic surgery residency training programs in Canada graduating an average of 6 to 8 residents per year. Prerequisites for training in a RCPSCaccredited thoracic surgery residency program include the completion and certification in general or cardiac surgery. In Canada, the duration of thoracic surgery residency is 2 years followed by a written and oral examination at the completion of training. Occasionally, residents will seek additional fellowship training. Future challenges in thoracic surgery education include refining the scope of practice for a practicing thoracic surgeon, accurately forecasting workforce needs and implementing the CBD framework in 2020.

The authors thank Ms Catherine MacPherson for her editorial assistance in preparing this manuscript.

\section{References}

1. Deslauriers JD, Nelms B, Pearson FG. Tribute to seven icons in the evolution of Canadian thoracic surgery over the 20th century. In: Deslauriers JD, Nelms B, Pearson FG, eds. Evolution of Thoracic Surgery in Canada. 1st ed. Hamilton: Decker Intellectual Properties; 2015:4-38.

2. Deslauriers JD, Nelms B, Pearson FG. Emergence of thoracic surgery as a specialty. In: Deslauriers JD, Nelms B, Pearson FG, eds. Evolution of Thoracic Surgery in Canada. 1st ed. Hamilton: Decker Intellectual Properties; 2015:170-3.

3. Mulder DS. Educating tomorrow's cardiac and thoracic surgeons in Canada: an evolving process. MJM. 1996;2:56-9.

4. Darling GE, Maziak DE, Clifton JC, Finley RJ. The practice of thoracic surgery in Canada. Can J Surg. 2004;47:438-45.

5. Royal College of Physicians and Surgeons in Canada. Objectives of training in the subspecialty of thoracic surgery. Available at: http://www.royalcollege. $\mathrm{ca} / \mathrm{cs} /$ groups/public/documents/document/y2vk/mdaw/ edisp/tztest3rcpsced 000459.pdf. Accessed September 3, 2016.

6. Royal College of Physicians and Surgeons in Canada. Accreditation of residency programs. Available at: http://www.royalcollege.ca/rcsite/education-strategyaccreditation/pgme-training-programs/accreditation-residency-programs-e. Accessed November 12, 2016.

7. CanMEDS 2015. Physician Competency Framework. Available at: http://www. royalcollege.ca/rcsite/documents/canmeds/canmeds-full-framework-e.pdf. Accessed September 3, 2016.
8. Royal College of Physicians and Surgeons in Canada. CanMEDS: Better standards, better physicians, better care. Available at: http://www.royalcollege. ca/rcsite/canmeds/canmeds-framework-e. Accessed September 3, 2016.

9. Frank JR, Danoff D. The CanMEDS initiative: implementing an outcomes-based framework of physician competencies. Med Teach. 2007;29:642-7.

10. Royal College of Physicians and Surgeons in Canada. National Curriculum Guide for Thoracic Surgery: Surgical and CanMEDS Competencies. Available at: http://www.royalcollege.ca/cs/groups/public/documents/document/mdaw/ mdyy/ edisp/062201.pdf. Accessed September 3, 2016.

11. Royal College of Physicians and Surgeons in Canada. Subspecialty Training Requirements in Thoracic Surgery. Available at: http://www.royalcollege.ca/cs/ groups/public/documents/document/y2vk/mdaw/ edisp/tztest3rcpsced000485. pdf. Accessed September 3, 2016.

12. Mulder DS, McKneally MF. The education of thoracic and cardiac surgeons: a Canadian initiative. Ann Thorac Surg. 1995;60:236-8.

13. Grondin SC, Schieman C, Kelly E, Darling G, Maziak D, Palacios MacKay M et al. A look at the thoracic surgery workforce in Canada: how demographics and scope of practice may impact future workforce needs. Can J Surg. 2013; 56:E75-81.

14. Schieman C, Kelly E, Gelfand G, Graham A, Mcfadden S, Edwards J, et al Thoracic surgery training in Canada according to the residents: the thoracic surgery resident survey, of the Canadian Thoracic Manpower and Education Study. J Surg Educ. 2010;67:325-34.

15. Edwards JP, Schofield A, Palucci EO, Schieman C, Kelly E, Servatyari R, et al Identifying areas of weakness in thoracic surgical residency training: a comparison of the perceptions of residents and program directors. J Surg Educ. 2014; 71:360-6.

16. Edwards J, Kelly E, Schieman C, Gelfand G, Grondin SC. Do new thoracic surgeons feel ready to operate? Self-reported comfort level of thoracic surgery trainees and junior thoracic surgeons with core thoracic surgery procedures. J Surg Educ. 2011;68:270-81.

17. Sundaresan S, McLeod R, Irish J, Burns J, Hunter A, Meertens E, et al Early results after regionalization of thoracic surgical practice in a single-payer system. Ann Thorac Surg. 2013;95:472-9.

18. Edwards JP, Datta I, Hunt JD, Stefan K, Ball CG, Dixon E, et al. A novel approach for the accurate prediction of thoracic surgery workforce requirements. J Thorac Cardiovasc Surg. 2014;148:7-12.

19. Edwards JP, Datta I, Hunt JD, Stefan K, Ball CG, Dixon E, et al. The impac of computed tomography screening for lung cancer on the thoracic surgery workforce. Ann Thorac Surg. 2014;98:447-52.

20. Edwards JP, Datta I, Hunt JD, Stefan K, Ball CG, Dixon E, Grondin SC. Forecasting the impact of stereotactic ablative radiotherapy for early-stage lung cancer on the thoracic surgery workforce. Eur J Cardiothorac Surg. 2016; 49:1599-606.

21. Takahashi SG, Abbott C, Oswald A, Frank JR. The big picture: connecting Competence by Design and CanMEDS 2015. In: Takahashi SG, Abbott C, Oswald A, Frank JR, eds. CanMEDS Teaching and Assessment Tool Guide. 1st ed. Ottawa: Royal College of Physicians and Surgeons of Canada; 2015:6-9.

22. Frank JR, Snell L, ten Cate O, Holmbee ES, Carracio C, Swing SR, et al Competency-based medical education: theory to practice. Med Teach. 2010;32 638-45. 